University of Nebraska - Lincoln

DigitalCommons@University of Nebraska - Lincoln

Biological Systems Engineering: Papers and

Publications

Biological Systems Engineering

September 2000

\title{
Fuzzy composite programming to combine remote sensing and crop models for decision support in precision crop management
}

David D. Jones

University of Nebraska-Lincoln, david.jones@unl.edu

E. M. Barnes

USDA-ARS, US Water Conservation Laboratory, Phoenix, AZ

Follow this and additional works at: https://digitalcommons.unl.edu/biosysengfacpub

Part of the Biological Engineering Commons

Jones, David D. and Barnes, E. M., "Fuzzy composite programming to combine remote sensing and crop models for decision support in precision crop management" (2000). Biological Systems Engineering: Papers and Publications. 2.

https://digitalcommons.unl.edu/biosysengfacpub/2

This Article is brought to you for free and open access by the Biological Systems Engineering at DigitalCommons@University of Nebraska - Lincoln. It has been accepted for inclusion in Biological Systems Engineering: Papers and Publications by an authorized administrator of DigitalCommons@University of Nebraska Lincoln. 


\title{
Fuzzy composite programming to combine remote sensing and crop models for decision support in precision crop management ${ }^{\text {ts }}$
}

\author{
D. Jones $^{\mathrm{a}, *}$, E.M. Barnes ${ }^{\mathrm{b}}$ \\ ${ }^{a}$ Biological Systems Engineering Department, University of Nebraska, Lincoln, NE 68583-07256 USA \\ ${ }^{\mathrm{b}} U S D A-A R S$, US Water Conservation Laboratory, Phoenix, AZ, USA
}

Received 9 February 2000; received in revised form 6 June 2000; accepted 13 June 2000

\begin{abstract}
Precision crop management is by definition a multi-objective decision-making process that must incorporate a diversity of data, opinion, preference and objective. This paper details an approach to decision making that allows users to express individual or corporate values and preferences; highlights the degree of imprecision associated with each input; highlights the degree of imprecision associated with each alternative; facilitates structuring of the decision process; reduces several levels of complex information into a single chart; allows examination of trade-off between alternatives and interests; and forces examination of inter-relationships between interest. The addition of using remote sensing data provides an efficient method to describe spatial variability in terms that can be related to a crop model, making the decisionmaking approach feasible for precision farming applications. The crop model provides information that can be used by the decision model, and the remote sensing data is used to fine tune the calibration of the crop model, maximizing the accuracy of its results. (C) 2000 Elsevier Science Ltd. All rights reserved.
\end{abstract}

Keywords: Decision making; Remote sensing; Precision farming; Precision crop management

is This manuscript has been assigned Journal Series No. 12846, Agricultural Research Division, University of Nebraska.

* Corresponding author. Tel.: + 1-402-472-6716; fax: + 1-402-4721-6338.

E-mail address: djones1@unl.edu (D. Jones). 


\section{Introduction}

\subsection{Precision farming strategy}

Precision crop management (PCM) has been defined as an "information- and technology-based agricultural management system to identify, analyze and manage site-soil spatial and temporal variability within fields for optimum profitability, sustainability and protection of the environment" (Robert et al., 1995). Considering this definition, it is first noted that a considerable amount of data will be required to assess and manage within field spatial and temporal variability. Secondly, PCM is defined as a multi-objective system that strives to optimize profitability, sustainability, and environmental protection. The implementation of a management system based on this definition is not a simple task. A proposed framework for incorporating a variety of data sources and models is shown in Fig. 1.

\subsubsection{Remotely sensed data}

The first component, remotely sensed data, is considered essential as this data can provide complete coverage of a farm at relatively frequent intervals. In the past, the use of remotely sensed data for farm management was limited by spatial and temporal resolution of civilian satellites (Jackson, 1984). However, the promise of new satellites with high spatial resolution and Internet delivery should reduce these limitations (Fritz, 1996). Additionally, reduced cost of digital camera systems and the possibility of multispectral sensors mounted on agricultural equipment will increase data availability.

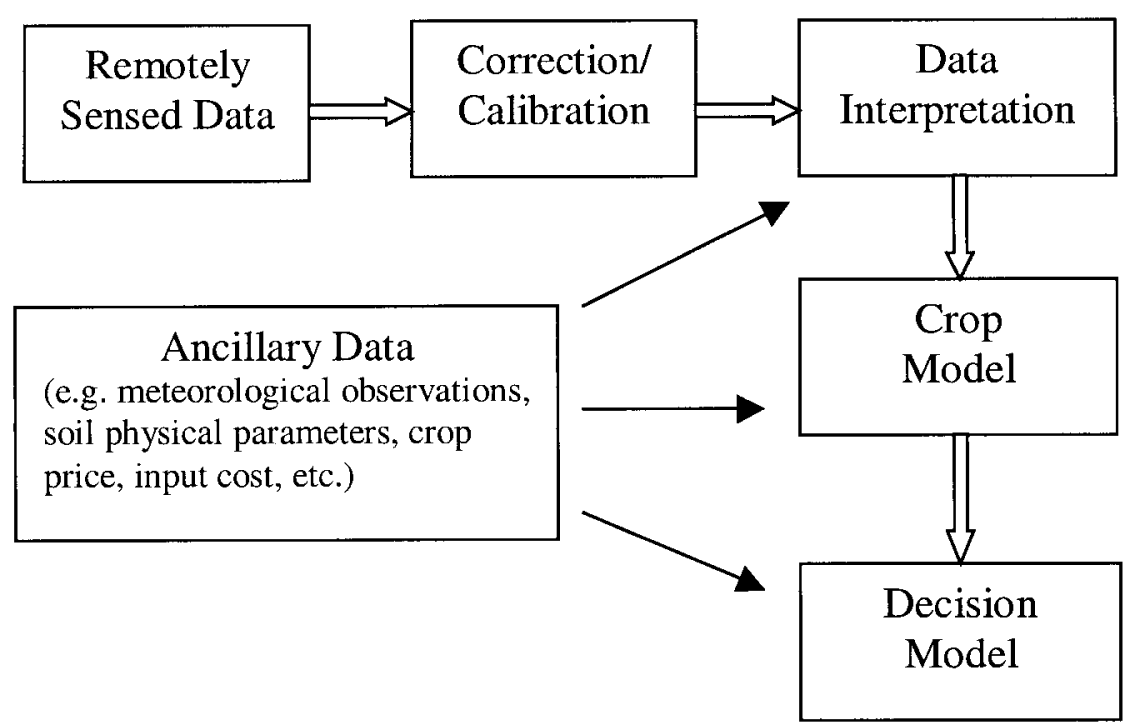

Fig. 1. Proposed decision-making framework. 


\subsubsection{Correction/calibration}

In order to establish temporally consistent, quantitative relationships between remotely sensed measurements and crop conditions, the data must first be calibrated. For satellite and aircraft data, this involves correcting for atmospheric interference, illumination intensity, and solar and viewing angles. Moran et al. (1997b) provide an overview of possible calibration methods specifically for airborne data, but some of the techniques presented could also be adapted for other platforms (satellite or equipment-mounted sensors). Precise geo-referencing of the data is required so the data can be directly integrated into a geographic information system (GIS).

\subsubsection{Remotely sensed data interpretation}

In the next component, the corrected information is interpreted with a data model to relate the reflectance or radiance to an agronomic parameter. Several relationships have been established between multi-spectral data and parameters that are relevant to PCM (Moran et al., 1997a). For example, remotely sensed data have been found useful to detect crop water stress (e.g. Clarke, 1997), map nitrogen deficiencies (e.g. Blackmer et al., 1996) and estimate absorbed photosynthetically active radiation (e.g. Pinter, 1993). While this is valuable information, it does not provide all the tools necessary for a grower to evaluate management decisions, nor does it identify which alternative best satisfies multi-objective criteria.

\subsubsection{Crop model}

The fourth component (crop models) provides the ability to project results for the rest of the growing season and test different management scenarios on the computer before they are implemented in the field. Because it is usually not feasible to collect enough plant-related data to characterize field-scale variability for use in PCM, the remotely sensed data are used as surrogates for crop growth observations in model calibration.

\subsubsection{Decision model}

The decision model is necessary to organize and compare alternatives and be capable of processing the multiple criteria set forth in the definition of PCM. Such an assessment system was developed by Hagemeister et al. (1996). For example, the predictions of yield from the crop model can be combined with ancillary data on production cost and crop price to estimate the profitability of different management approaches. Data on nitrogen leaching and crop water use for the various management scenarios provide the decision model with information on sustainability and environmental protection. The decision model then ranks the proposed management options in terms of profitability, sustainability, and environmental protection.

\subsubsection{GIS}

A GIS is a key component in managing both remotely sensed and ancillary data (e.g. Usery et al., 1995). The GIS could contain soil sample results (e.g. fertility and texture), variable rate application information, and historic yield maps. The GIS can 
be arranged to define areas with similar soil properties, application rates and plant response where both the crop and decision models can be executed.

\subsection{Objective}

The objective of this paper is to present a framework in which remotely sensed data, crop models, and a decision model can be integrated to meet the PCM definition with emphasis on the decision model. A simple example is presented to demonstrate each component of the framework.

\section{Literature review}

Extensive literature reviews have been published on the application of remote sensing to PCM (Moran et al., 1997a) and the integration of crop models and remote sensing (Moulin et al., 1998). Therefore, the literature review presented will focus on decision models.

\subsection{Overview of decision models}

\subsubsection{Multi-objective decision making}

Decision models and decision-making tools have been developed over a number of years. Many of them are over-simplified to the point that they lack utility. Others become so complex and detailed that the focus turns from decision making to data collection. The type of decision models appropriate for application to PCM is classified as multi-criteria, multi-objective, competing objective, multi-attribute and a number of other descriptors. The common component is that complete agreement about a single objective of the decision is not achieved. Therefore the decision maker is left to balance these competing issues.

A number of approaches have been used. Wei and Weber (1995) incorporated expert opinion to address multi-criteria decision making for waste management concerns. Lawrence et al. (1997) used a similar approach but combined measured data and expert opinion to address semi-arid rangeland concerns.

Yakowitz et al. (1993) examined a technique to rank the priorities associated with the importance of contributing attributes of the decision in question. This technique allows the user to determine the influence of advocacy and the sensitivity of the overall decision to that advocacy. This technique has been applied to environmental management (Yakowitz and Hipel, 1997), and water quality and economics (Heilman et al., 1997).

\subsubsection{Fuzzy composite programming (FCP)}

FCP is a distance-based multi-objective optimization problem that uses fuzzy representation of uncertainty (Bardossy and Duckstein, 1992). Examples of FCP methodology include management of a karstic aquifer (Bardossy and Duckstein), nitrate risk management (Lee et al., 1992), management of dredged material (Lee et 
al., 1991) and landfill hazard ranking (Hagemeister et al., 1996). In each case previously mentioned, as well as the example described in this paper, the authors use fuzzy sets to describe the inherent imprecision and ambiguity associated with the decision-making variables.

Crisp or non-fuzzy compromise programming, forms the basis for composite programming and employs a single-level non-normalized distance-based methodology (Zeleny, 1973). Bardossy et al. (1985) developed composite programming that extended compromise programming to a normalized multi-level methodology. Woldt and Bogardi (1992) have used composite programming to develop a methodology for designing a groundwater monitoring network that can be used to detect and map environmental contamination. The addition of fuzzy set theory (Zadeh, 1965) to compromise programming is used to represent uncertainties of the indicators. In a manner similar to the composite programming extension, fuzzy compromise programming can be extended to a normalized multi-level distance-based methodology to account for uncertainties, also known as FCP (Bardossy and Duckstein, 1992).

Zadeh (1965) proposed the use of fuzzy set theory (FST) to describe relationships that are best characterized by compliance to a collection of attributes. The theory allows for membership in fuzzy set to be partial. The partial or fuzzy membership is scaled from 0 (no membership) to 1 (complete membership). The use of FST has grown to include a wide variety of applications ranging from machine control to management (Ross, 1995). One use of FST is the interpretation of linguistic information. This is useful since many phenomena are described using linguistic descriptions rather than quantitative measures. This is particularly true when interpreting preferences or judgements (DiFrancesco et al., 1998).

\section{Material and methods}

\subsection{Site description}

The framework is demonstrated using data collected during the 1994 cotton season at the University of Arizona's Maricopa Agricultural Center (MAC, 33 $04^{\prime} 21^{\prime \prime}$ $\left.\mathrm{N} ; 111^{\circ} 58^{\prime} 45^{\prime \prime} \mathrm{W}\right)$. MAC is 770 ha and located approximately $40 \mathrm{~km}$ south of Phoenix at an elevation of $360 \mathrm{~m}$. This is an arid area, receiving only $185 \mathrm{~mm}$ of rainfall per year and average summer temperatures ranging from 25 to $42^{\circ} \mathrm{C}$.

\subsection{Remotely sensed data}

Airborne data, acquired on 15 dates from April to September 1994 over the MAC in Central Arizona, were used to demonstrate the framework. The imagery had a 2$\mathrm{m}$ spatial resolution in the green $(0.545-0.555 \mu \mathrm{m})$, red $(0.645-0.655 \mu \mathrm{m})$, and near infrared (NIR, $0.840-0.860 \mu \mathrm{m})$ region of the spectrum. Additional details on the airborne data set are given by Moran et al. (1996). This study focused on one area of the farm where the imagery provided indications of spatial variability in cotton 
development (Fig. 2). Fig. 2 shows both an interpolated soil map from Barnes and Baker (1999) and a ratio vegetation image $(\mathrm{RVI}=\mathrm{NIR} / \mathrm{red})$ for 6 July of the area considered. This date was chosen as the cotton had not reached full cover $(50-90 \%$ cover, leaf area indexes [LAIs] ranging from 0.8 to 2.6), allowing better representation of the spatial patterns in canopy development in the RVI image. The cotton was in the flowering stage of development at this time.

There is good agreement between the spatial distribution of the surface soil texture and RVI levels. The entire area received the same amount of irrigation; thus it is probable the sandy loam areas with lower water-holding capacity experienced greater water stress during the season than those soils with higher clay content.

\subsection{Calibration}

Digital numbers corresponding to the visible and NIR bands were converted to reflectance utilizing data from calibrated canvas tarps. Ground-based radiometer measurements of a bare field concurrent with time of the over flights were also used in the calibration procedure (see Moran et al., 1996, for details on the calibration procedures). The imagery was also manually registered to a Universal Transverse Mercator projection utilizing an existing GIS vector coverage of the farm.

\subsection{Remotely sensed data interpretation}

Coincident observations of red and NIR reflectance from a hand-held radiometer and LAI were available for the study site from Pinter et al. (1994). Simple linear regression was determined to provide a suitable relationship between the reflectance and LAI data as illustrated in Fig. 3. This relationship was used with the calibrated

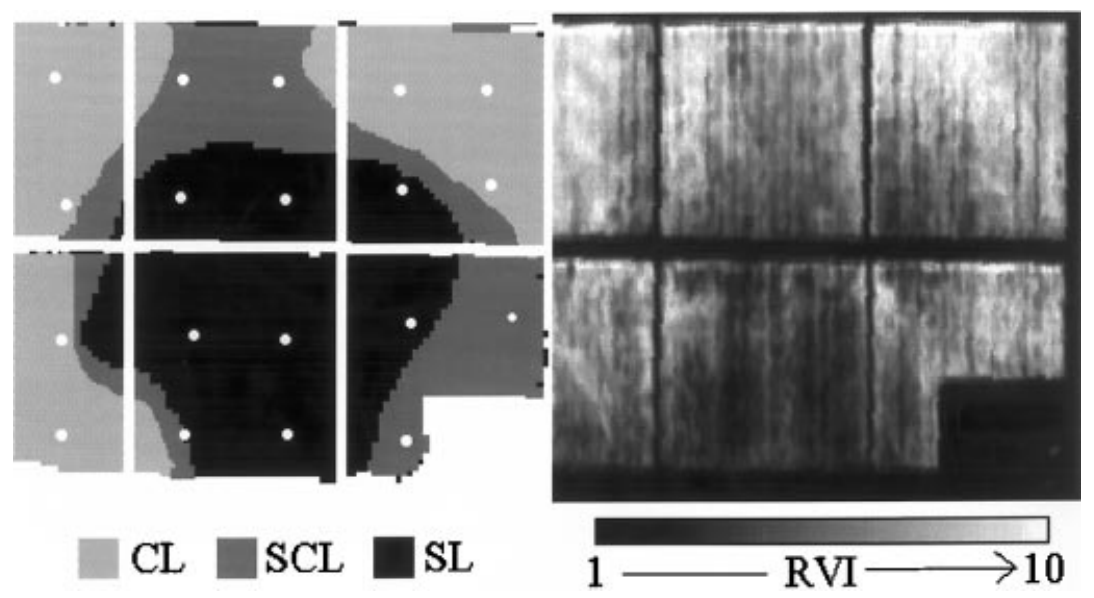

Fig. 2. Interpolated soil map (left) and ratio vegetation index (RVI) image from 6 July (right) of the study area. In the soil map, CL represents the area of the field with a clay loam surface soil texture, SCL sandy clay loam, SL sandy loam, and the circles indicate approximate soil sample locations. 


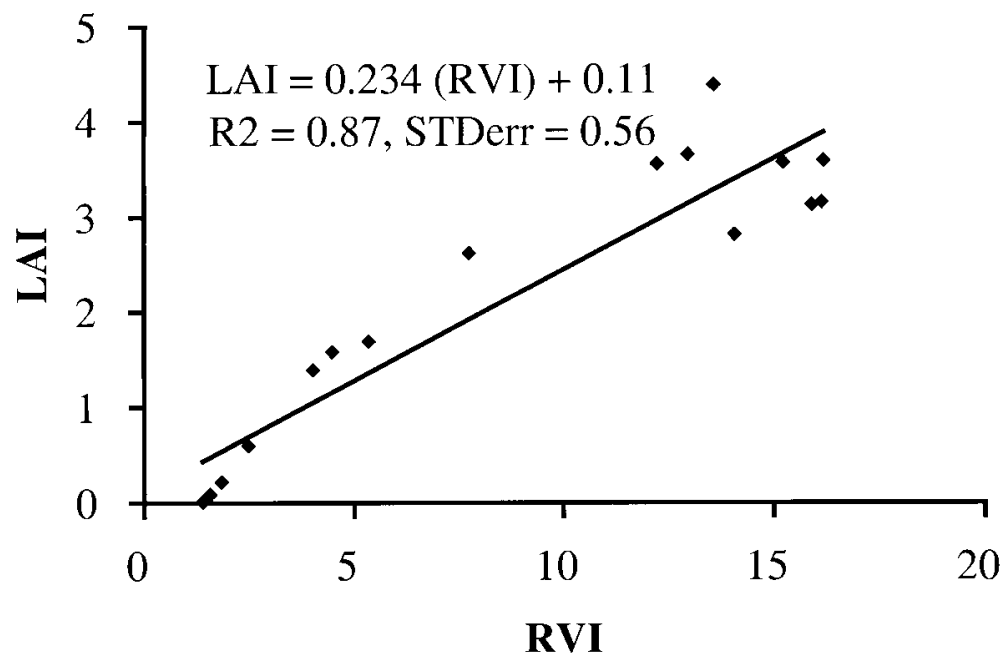

Fig. 3. Relationship used to relate the ratio vegetation index (RVI) to leaf area index (LAI) for cotton at the Maricopa Agriculture Center.

imagery to generate LAI maps from flight data. The mean values corresponding to the areas of clay loam and sandy loam soil textures in Fig. 2 were then determined. The sandy clay loam area was not considered in the analysis as it occupied a smaller area and vegetation density estimates from the imagery indicated that this area did not vary significantly from the clay loam areas.

\subsection{Crop model}

The CALGOS (CALifornia GOSym, ) cotton growth model was selected because this model is a modified form of GOSSYM (Baker et al., 1983) for semi-arid conditions (Marani et al., 1992). The model can provide prediction of cotton growth and development in response to variation in meteorological, soil water, and soil nitrogen conditions. Management practices (i.e. tillage, planting, irrigation, fertilizer applications) were determined from farm records and input to the crop model for the 1994 growing season. Meteorological data was available from a station operated on the farm (air temperature, humidity, wind speed, rainfall). Variety-specific calibration of the model for the study site was already available from Marani (personal correspondence, A. Marani, Visiting Scientist, USDA, ARS Water Management Research Laboratory, Fresno, CA, USA) using data from Mauney et al. (1994). The cotton model also requires volumetric release curves for each soil type to be simulated; however, soil data specific to the fields considered was limited to sand, silt and clay percentages. Therefore, the cotton model's soil parameters related to waterholding capacity were adjusted until predictions of LAI were consistent with the remotely sensed estimates. The emergence date input to the model was also adjusted to improve agreement between the model's predictions and remotely sensed estimates of LAI. The 'calibrated' model outputs compared to the remotely sensed 
estimates are shown in Fig. 4. This calibrated version of model was then used to supply information on yield and nitrogen use to the decision model and to simulate a different irrigation schedule (described in more detail in a later section). For this demonstration, only a single year was simulated for each of the scenarios considered. In practise, simulations for a number of meteorologically different years (either from generated or measured data) should be used to determine the uncertainty in the estimates due to weather conditions.

\subsection{Description of decision model}

The overall structure of the decision model must accommodate the consideration of conflicting and competing objectives. Each of these objectives must be fully developed independently of the other objectives. In this case, those competing objectives include profitability, preserving the environment, and maintaining sustainability. Computational aspects of the fuzzy composite programming methodology are detailed in the Appendix.

\subsubsection{Model structure}

The decision-making model is a hierarchical structure. At the top of the hierarchy is the overall decision. This decision must balance the need for profitability, environmental concerns, and the need to maintain a sustainable system. This simple structure is shown in Fig. 5.

3.6.1.1. Profitability. The profitability of the system is based upon the lint yield, the lint price, the cost of irrigation water, and the operating cost associated with

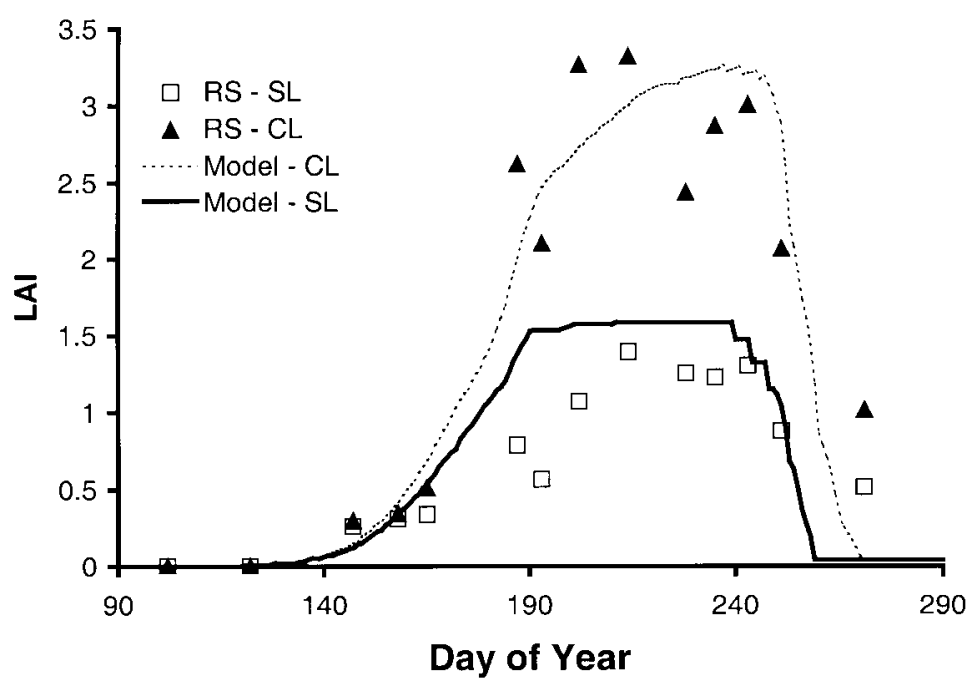

Fig. 4. Model predicted (Model) and remote sensing (RS) observations of leaf area index (LAI) for the sandy loam (SL) and clay loam (CL) soil types during the 1994 cotton growing season. 


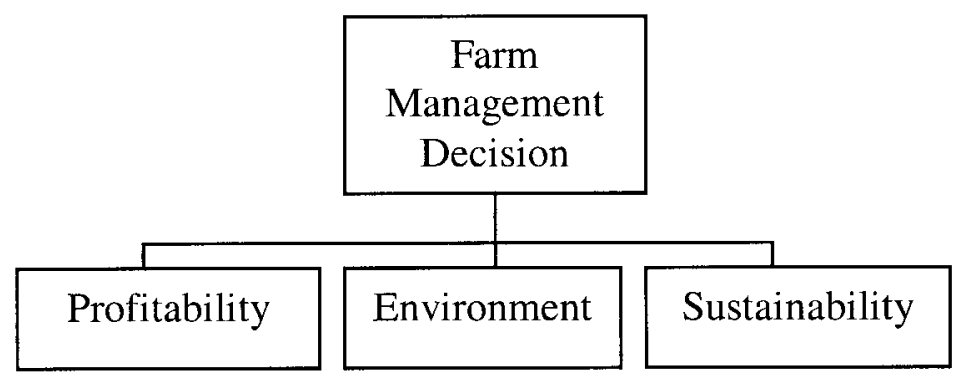

Fig. 5. Decision-making structure.

producing the crop. In this decision model, the units of profitability were dollars per hectare. The ambiguities associated with each of the factors that constitute profitability are represented as fuzzy numbers. The arithmetic processes needed to calculate the profitability followed the vertex method as outlined by Dong and Shah (1987).

3.6.1.2. Lint yield. Lint yield was determined using the CALGOS growth model (Marani et al., 1992). The predicted lint yield changed as different irrigationmanagement practices were used and different soil types were encountered. The units on lint yield were tonnes of lint per hectare.

3.6.1.3. Lint price. The lint price was determined from prices reported by Arizona Cooperative Extension (1996). The price was assumed to be most likely between $\$ 1321.59$ and 1585.90 per tonne but could be as low as $\$ 660.79$ and as high as $\$ 1762.11$ per tonne of lint. The same price structure was used for each of the alternatives. Note that an economic model to predict future trends in lint price could be incorporated as part of this system to reduce the uncertainty in this estimate. For the sake of this demonstration, the variability associated with the lint price was arbitrarily assigned in order to give an example of how intuition and native knowledge can be incorporated into the decision process.

3.6.1.4. Irrigation water costs. The inputs to the growth model include the amount and timing of irrigation water that matches the management strategy under consideration. The per unit cost associated with purchasing the irrigation water was determined from Arizona Cooperative Extension (1996) which was reported to be \$284 per ha-m. This value was used for each of the alternatives. The total cost of irrigation water was determined by multiplying the unit cost for irrigation water and the amount of irrigation water used.

3.6.1.5. Operating costs. The labor costs associated with applying the irrigation water using conventional management practices were determined from Arizona Cooperative Extension (1996) and were estimated to be $\$ 74$ per ha for the "normal irrigation' alternative. This cost is compared to an estimated value of $\$ 1236$ per ha for the 'linear move' management alternative. The difference in cost is reflective of the increase capital requirements of the 'linear move' alternative. 
3.6.1.6. Environmental. Environmental impacts can be measured in a number of ways. The impact of irrigation and cotton production is easily seen in the quantity of nitrogen that is leached from the soil resulting from cultural and management practices. The CALGOS model, using the various management practices, was used to determine the amount of nitrogen remaining in the soil. The type of soil, amount of fertilizer applied, and type of irrigation strategy influenced the amount of nitrogen remaining in the soil. For each alternative and soil type, 0.157 tonnes of nitrogen per ha was applied during the growing season. It was considered an advantage to the environment when less nitrogen was left in the soil at the end of the growing season. In this decision model, the units of the environmental variable were tonnes of nitrogen per hectare. The CALGOS model reported the nitrogen uptake by the crop and the amount of fertilizer remaining in the soil during the growing season.

3.6.1.7. Sustainability. Sustainability is a concept that most agree is important but little agreement exists on how to define it. In this scenario, sustainability was related to the amount of water used for irrigation. The amount of water used for irrigation was determined using the CALGOS model and farm records from 1994 cotton season. In this decision model, sustainability was assessed as 'low', 'medium', or 'high', represented as a fuzzy number. Fuzzy numbers have been used to describe linguistic descriptions of phenomenon and are described in Ross (1995) and Jones and Jones (1999).

\section{Decision-making scenario}

To illustrate this methodology, consider the following decision-making scenario. A decision maker (DM), such as a farm manager in Arizona, is considering how to manage the irrigation scheduling for two different fields each with a unique soil type, namely, sandy loam and clay loam. Note that this example is limited to these two soil types, but when applied across an entire farm, each soil type present would require evaluation. Cotton is grown on each of the fields and three different irrigation/ management strategies are available. Those strategies are described as a normal irrigation practice, irrigation with a linear move system, and not plant a crop at all. Considering these alternatives, the manager is left to choose the best management for each of the fields. The decision is complicated by the need to balance the need for profitability, environmental impact, and sustainability.

\subsection{Assignment of weights and balancing factors}

Prior to examining alternatives the DM must describe the constraints and decisionmaking criteria needed to objectively evaluate alternatives. Generally, this is an internal process that is not typically well defined or thoroughly documented. The description is in part the structure of the contributing factors as illustrated in Fig. 5, but also includes the knowledge and preferences of the DM. 
To capture the knowledge and preferences of the DM, weights are used to indicate the importance of competing objectives. Note that the weights are determined by the DM and will change for different DMs. For this example, the weights were valued as real numbers to simplify the example for illustrative purposes. The goal is to capture the intent of the DM and describe that intent in mathematical terms. They could be valued as fuzzy variables, ranks, or scaled ranks to provide a more realistic description of the contributing factors.

Consider the farm management decision. As illustrated in Fig. 5, this decision is composed of Profitability, Environment, and Sustainability. The DM must indicate as completely as possible the relative weight and relationship of each of these contributors. For the sake of this example, assume that the DM is most concerned with Profitability, least concerned with Sustainability and somewhat concerned about Environmental. The resulting weights of the contributors using this example are shown in Table 1 . Note that the weights for each contributor must sum to 1 and each must be between 0 and 1 . Also included in Table 1 is the balancing factor. The balancing factor is a computational necessity and is a measure of the exchangeability of the contributors to each group. Descriptions of these and other computational aspects of these details are described in the Appendix.

\subsection{Description of alternatives}

Three irrigation management alternatives were developed for each of the two fields. Recall that each of the fields have a unique soil type, namely, sandy loam and clay loam. Each alternative had unique and various costs and consequences that impacted the acceptance of the alternatives. The consequences of each alternative are outlined below.

The alternatives denoted as 'normal irrigation' attempted to represent typical irrigation scheduling and management in the area and were based on the actual irrigation amounts applied to the fields in 1994 cotton season. The alternatives denoted as 'linear move irrigation' attempted to represent an idealized or perfect irrigation. As determined by the CALGOS model, the crop was irrigated with the exact quantity and at the exact time the crop required irrigation. Associated with the application of the irrigation were labor and capital costs. The alternatives denoted as 'do not plant' attempted to represent the 'do nothing' alternative. A summary of the consequences of each alternative is shown in Tables 2 and 3.

Table 1

Assignment of weights and balancing factors for decision model representing preferences of a hypothetical decision maker concerned mostly about 'profitability'

\begin{tabular}{llll}
\hline Overall decision & Balancing factor & Group & Weights \\
\hline & & Profitability & 0.5 \\
Farm management decision & 3 & Environment & 0.3 \\
& & Sustainability & 0.2 \\
\hline
\end{tabular}


Table 2

Description of contributors for sandy loam soil

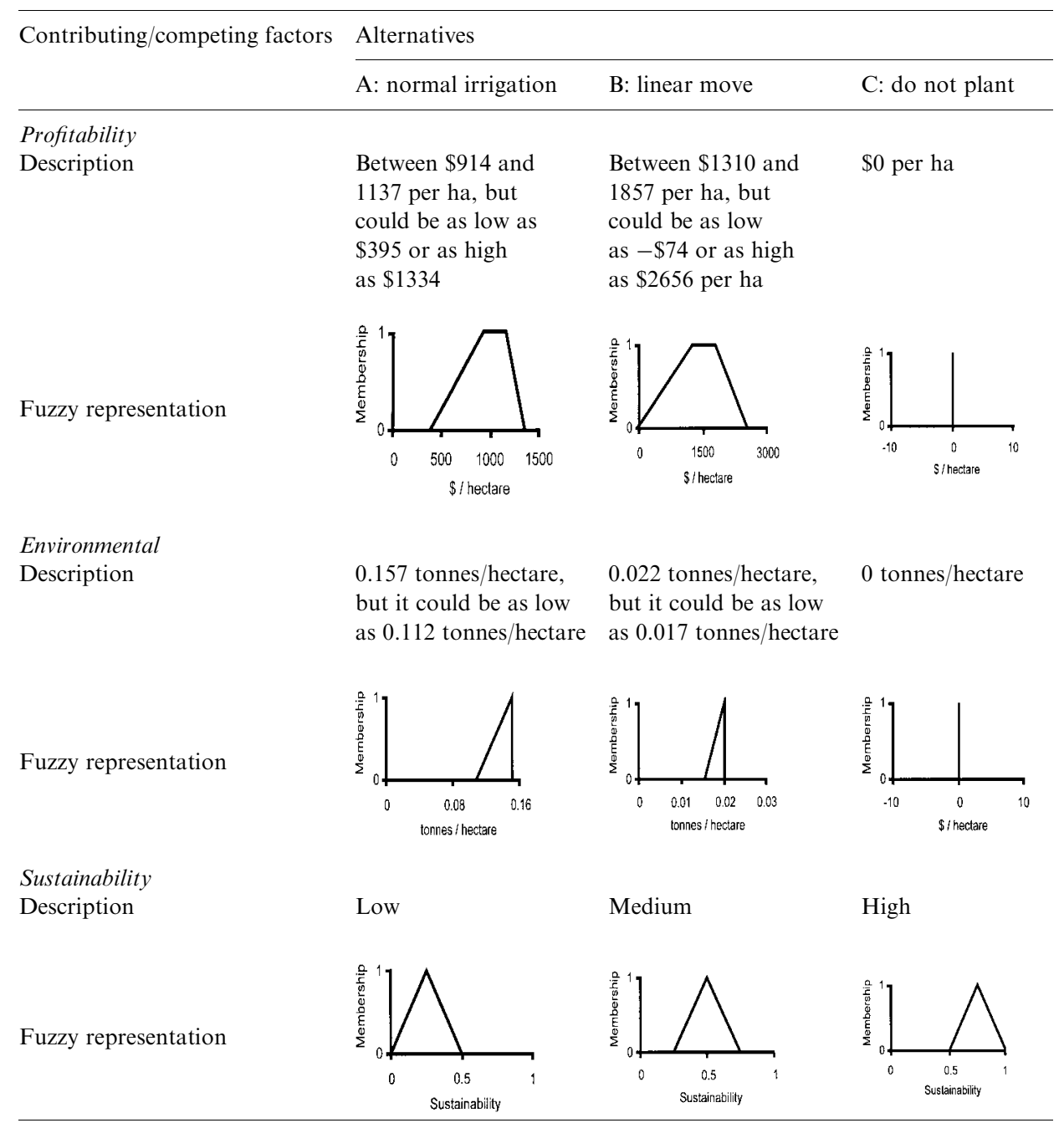

Each of the six alternatives described in Tables 2 and 3 are similar in construction. To illustrate the development of each of the alternatives, consider Alternative A: normal irrigation (in the field with sandy loam soil). The alternatives were similarly developed and are summarized in Tables 2 and 3. The contributing factors for each alternative were considered individually.

\subsubsection{Profitability}

The profitability of the system is based upon the lint yield, the lint price, the cost of irrigation water, and the operating cost associated with producing the crop. Lint 
Table 3

Description of contributors for clay loam soil

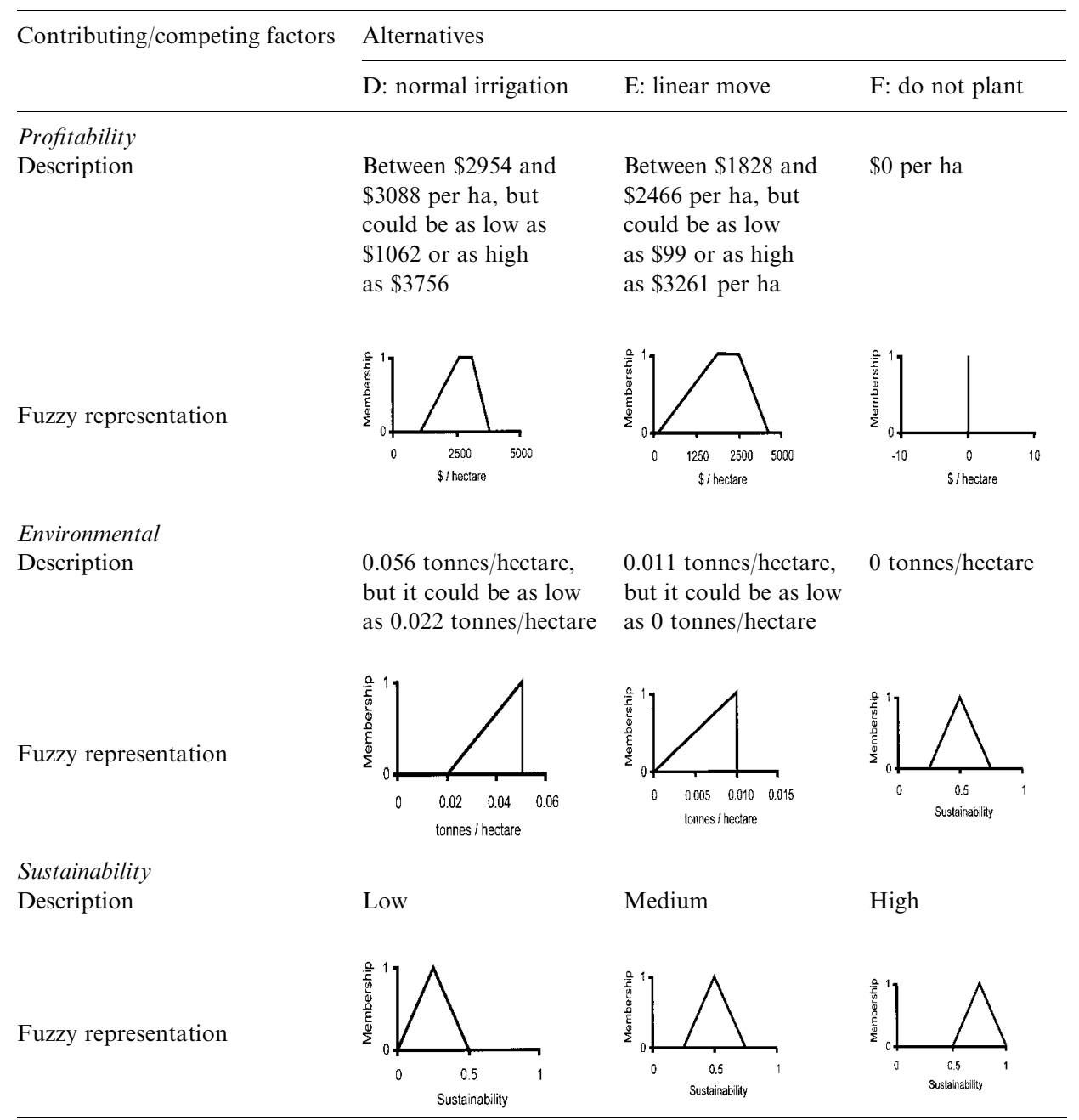

yield was determined using the CALGOS growth model (Marani et al., 1992) to be 0.823 tonnes of lint per ha. It was recognized that the CALGOS model is not exact, having predictions more than $50 \%$ different than observed yield in the validation data set. However, the relative response to different input variables more closely matched observed relative responses. As the goal is to compare between different alternatives, the yield predictions from the model were assumed to be within $5 \%$. In other applications, a larger range of yield may be appropriate. Therefore, the yield was described as being 0.823 tonnes per ha but it could be as low as 0.786 or as high as 0.865 tonnes of lint per ha based on the accuracy of the model with validation 
data sets. By combining the assumed range in lint price with these yield estimates, the profitability was determined to be between $\$ 914$ and 1137 per ha but could be as low as $\$ 395$ or as high as $\$ 1334$ per ha.

\subsubsection{Environment}

Environmental considerations were measured by the amount of nitrogen fertilizer remaining in the soil as determined by the CALGOS growth model (Marani et al., 1992). For this alternative the model predicted that 0.157 tonnes of nitrogen per ha remained in the soil. It was recognized that the CALGOS model is not exact; therefore, the amount of nitrogen remaining in the soil was described as being 0.157 tonnes per ha, but it could be as low as 0.112 tonnes per ha.

\subsubsection{Sustainability}

Sustainability was measured by the amount of water used to irrigate the crop. For this alternative the sustainability was considered 'low' since it is based upon 'normal' irrigation practices which requires the most water. Furthermore, the low designation is warranted given a comparison to the other alternatives investigated.

\subsection{Description of 'worst' and 'best' parameters}

The computational algorithms require normalized values; therefore, 'Worst' and 'Best' values for each contributor must be determined. This process is explained in detail in the Appendix. Similar to each of the other values, these values can be linguistic, crisp, fuzzy, etc. The 'Worst' and 'Best' values used in this example are shown in Table 4.

The 'Worst' and 'Best' values for the Profitability contributors were determined directly from the fuzzy representations of each of the costs. The worst case corresponded to a profitability of $-\$ 74$ per ha whereas the best case corresponded to profitability of $\$ 3756$ per ha. The 'Worst' and 'Best' values for the environmental contributor was determined directly from the fuzzy representations of each of the variables. The worst case corresponded to 0.157 tonnes of nitrogen per ha and the best case corresponds to 0 tonnes of nitrogen per ha. The 'Worst' and 'Best' values for the Sustainability contributor was determined to be 0 for the worst case and 1 for the best case. Further development and description of the computational aspects are given in the Appendix.

Table 4

Worst and best values for each contributor

\begin{tabular}{lll}
\hline Contributors & Worst & Best \\
\hline Profitability & $-\$ 74$ per hectare & $\$ 3756$ per hectare \\
Environmental & 0.157 tonnes of nitrogen per ha & 0 tonnes of nitrogen per ha \\
Sustainability & 0 & 1 \\
\hline
\end{tabular}




\section{Results and discussion}

Fuzzy representations of the results are shown in Figs. 6 and 7. The $x$-axis in Figs. 6 and 7 is the fuzzy distance towards the ideal solution (Bardossy and Duckstein, 1992). A value of 1 on the $x$-axis would indicate that the ideal solution has been achieved. A value of 0.5 indicates that the solution is one-half the distance between the worst solution and the ideal solution. The $y$-axis indicates the membership (or degree of belonging) of each alternative to its position towards the ideal solution.

The results in Figs. 6 and 7 can be interpreted by saying that Alternative A will most likely perform between 0.6 and 0.65 of the ideal solution (range where the

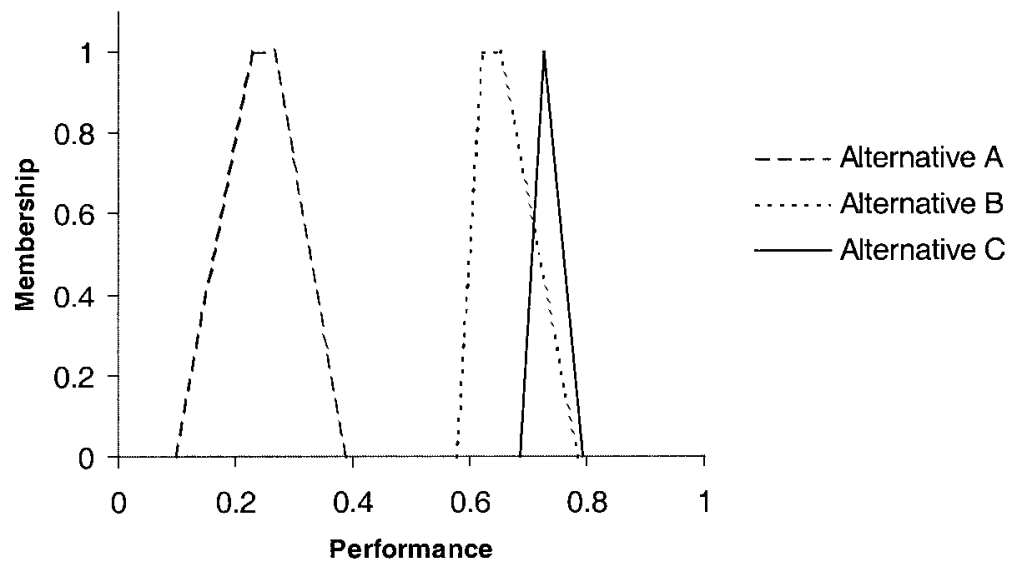

Fig. 6. Fuzzy performance of alternatives for sandy loam soil using weights and balancing factors as shown in Table 1.

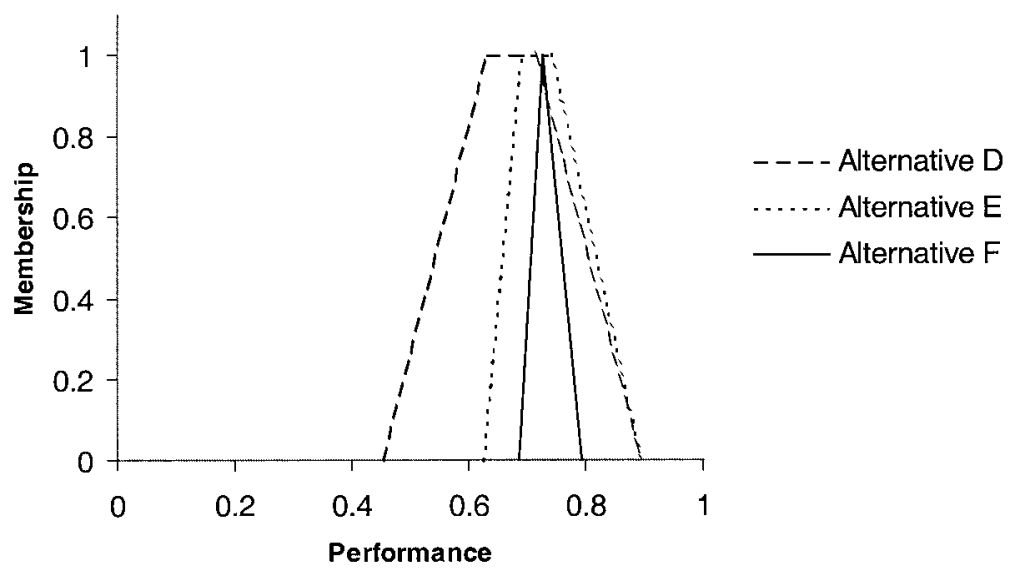

Fig. 7. Fuzzy performance of alternatives for clay loam soil using weights and balancing factors as shown in Table 1. 
membership is 1); it could perform as low as 0.58 , or as high as 0.78 of the ideal solution. Each of the alternatives could be similarly interpreted.

There are several ways to 'defuzzify' results such as those presented in Figs. 6 and 7. The techniques include determining centers of mass, weighted averages, etc. For this example, the practical interpretation is to choose the alternative that most closely conforms to the description of the ideal solution. The breadth, or spread, of the curves representing each alternative in Figs. 6 and 7 is meaningful. The ambiguities captured in the first-level indicators have been propagated through the systems and are now manifest in Figs. 6 and 7. A wider spread represents more ambiguity or uncertainty. Conversely, a narrower spread indicates less.

The performance of the management alternatives for growing cotton on a sandy loam soil, as depicted in Fig 6, indicate that Alternative C, 'do not plant', more closely conforms to the ideal solution. This is evident since the curve representing this alternative is closer to 1 than any of the other alternatives. Similarly, it is obvious that Alternative A, 'normal irrigation', performs worse than the other two alternatives.

When examining the results for growing cotton on a clay loam soil presented in Fig. 7, the best alternative is not as clearly determined. The curves representing the performance of each of the alternatives are grouped closely together and less distinction between alternatives is evident.

Adjusting the weights applied to each of the contributors will result in different performance of each of the management alternatives. The results shown in Figs. 8 and 9 reflect the performance of the alternatives when the weights are assigned as indicated in Table 5. The weights indicated in Table 5 are representative of a DM who has different goals and objectives for the farming operation.

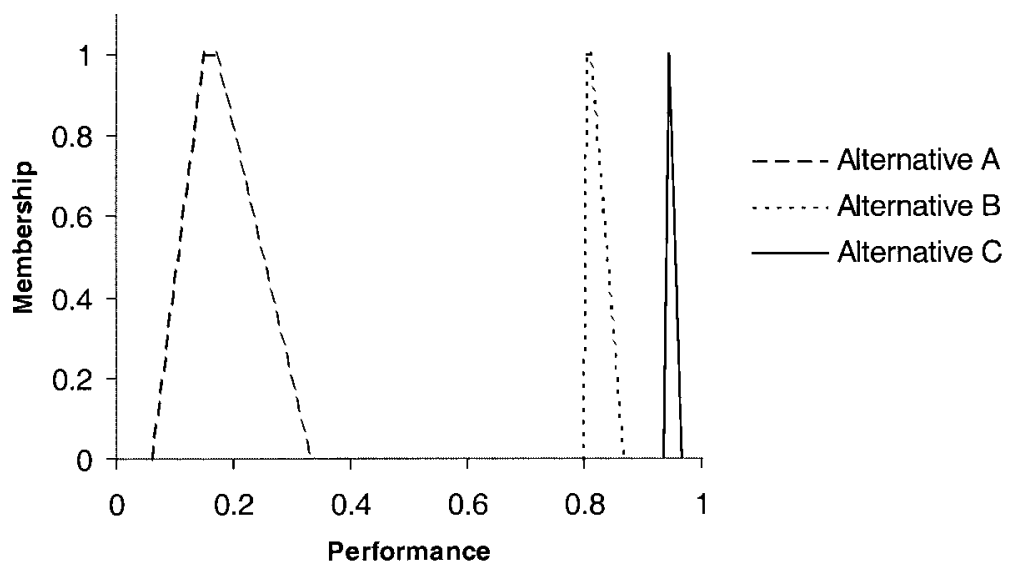

Fig. 8. Fuzzy performance of alternatives for sandy loam soil using weights and balancing factors as shown in Table 5. 


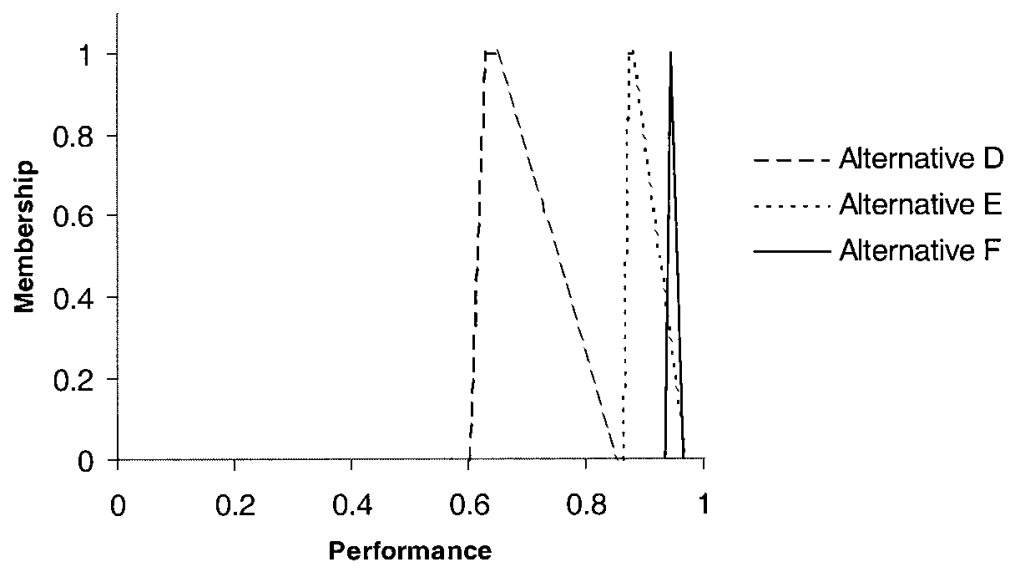

Fig. 9. Fuzzy performance of alternatives for clay loam soil using weights and balancing factors as shown in Table 5 .

Table 5

Assignment of weights and balancing factors for decision model representing preferences of a hypothetical decision maker concerned mostly about 'environment'

\begin{tabular}{llll}
\hline Overall decision & Balancing factor & Group & Weights \\
\hline & & Profitability & 0.1 \\
Farm management decision & 3 & Environment & 0.8 \\
& & Sustainability & 0.1 \\
\hline
\end{tabular}

\section{Summary and conclusions}

This approach to decision making is useful for a variety of reasons, including that it:

1. allows users to express individual or corporate values and preferences;

2. highlights the degree of imprecision associated with each information source used (i.e. model accuracy, uncertainty in costs and returns, etc.;

3. highlights the degree of imprecision associated with each alternative;

4. facilitates structuring of the decision process;

5. reduces several levels of complex information into a single chart;

6. allows examination of trade-off between alternatives and interests; and

7. forces examination of inter-relationships between interest.

The addition of remote sensing provides an efficient method to describe spatial variability in terms that can be related to a crop model, making the decision-making approach feasible for precision-farming applications. The crop model provides information that can be used by the decision model, and the remote sensing data is used to fine tune the calibration of the crop model, maximizing the accuracy of its results. 
Many layers of complexity could have been added to the example presented, such as simulation of multiple weather seasons, economic forecasts and consideration of numerous other alternatives. Consideration should be given to these additions before such an approach is applied to an actual problem.

\section{Appendix A}

The computational aspects of the problem solution begin with normalization. Each of the input variables must be normalized. The normalization process is performed by using best and worst values for the first-level indicators. The best and worst values for the first level indicators are determined by the user and are detailed in Table 4. Bardossy and Duckstein (1992) noted that the best and worst values might be crisp or fuzzy. For this example, the best and worst values are assumed to be crisp.

The normalization is performed with the following equation (Bogardi, 1992; Hagemeister et al., 1996).

$$
\begin{aligned}
& S_{i}^{\prime}=\frac{Z_{i}^{\prime}-Z \min _{i}}{Z \max _{i}-Z \min _{i}} \text { when } Z \max _{i} \text { is best, or } \\
& S_{i}^{\prime}=\frac{Z \max _{i}-Z_{i}}{Z \max -Z \min _{i}} \text { when } Z \min _{i} \text { is best }
\end{aligned}
$$

where $S_{i}^{\prime}=$ normalized $i$ th fuzzy indicator; $Z_{i}^{\prime}=$ value of the $i$ th fuzzy indicator; $Z \max _{i}=$ maximum possible value of the $i$ th indicator; and $Z \min _{i}=$ minimum possible value for the $i$ th indicator.

Consider the contributor of profitability. The best value is $\$ 3756$ per ha and the worst value is $-\$ 74$ per ha. Consider also Alternative A (normal irrigation on sandy load soil). The normalized value, using the previous equation can be described as the profitability could be as low as 0.12 or as high as 0.37 (where membership $=0$ ) but most likely between 0.26 and 0.32 (where membership $=1$ ). Notice that this process not only normalizes the variable but non-dimensionalizes it well. This process is repeated for each of the contributing factors for each alternative.

The hierarchical structure of this technique is used to aggregate the fuzzy indicators into more complex second-level fuzzy indicators. This process of aggregation continues until the final-level fuzzy indicator is achieved. The aggregation process is accomplished by combining weighted fuzzy distances. This process is described more completely below. In this example, only first level indicators are used (Fig. 5) to aggregate into the overall decision. In more complex representations, additional levels of indicators can be included.

The final result will include inevitable uncertainties and ambiguities due to imprecise first-level indicators and best and worst cases. Their structure can be established such that first-level indicators will utilize known or relatively easily obtained information, which lead to ranking or assessment of a very complex system. 
The sets of related normalized first-level fuzzy indicators are fuzzy distances and are combined to obtain their respective second-level fuzzy composite distance. The process of computing successive levels of fuzzy composite distances is repeated until a final fuzzy composite distance is reached for the system. This final-level fuzzy indicator composite distance represents the compliance of the particular alternative to the description of the ideal solution as measured by a fuzzy composite distance. The fuzzy composite distance is obtained by the following equation (Bogardi, 1992; Hagemeister et al., 1996).

$$
L_{j}^{\prime}=\left[\sum_{i=1}^{n_{j}}(\omega)_{i, j} \times\left(S_{i, j}^{\prime}\right)^{p_{j}}\right]^{\frac{1}{p_{j}}},
$$

where, $L_{j=}^{\prime}$ fuzzy composite distance for group $j$ of the indicators; $S_{i, j}^{\prime}=$ normalized fuzzy value of the input element indicator $i$ in group $j$; $\omega_{i, j}=$ weights expressing the relative importance of indicators in group $j$ such that their sum is $1 ; p_{j}=$ balancing factors among indicators for group $j$; and $n_{j}=$ number of indicators in group $j$. In this example, $j=1$ since there is only one group as shown in Fig. 5. There are three indicators (profitability, environmental, and sustainability) in this group therefore $n_{j}=n_{1}=3$.

The weight parameters and balancing factors must be specified by the DM. These weight parameters are established based on the degree of importance the DM considers each indicator possesses relative to other indicators of the same group. Therefore, the DM is expected to identify preferences in the analysis. Note that the weights must sum to 1 and each must be between 0 and 1 . The weight parameters were assumed to be crisp and therefore valued as real numbers to simplify the example for illustrative purposes. The goal is to capture the intent of the DM and describe that intent in mathematical terms. In one part of this example, the DM is assumed to be mostly concerned about profitability and the associated weights are shown in Table 1. Alternatively, the weights shown in Table 5 reflect a DM concerned mostly with environmental objectives.

The balancing factors must also be specified by the DM. In one part of this example, the balancing factor for the one group is found in Table 1. Balancing factors reflect the importance of the maximal deviations between indicators in the same group. In other words, balancing factors determine the degree of substitution between indicators of the same group. Low balancing factors (i.e. near 1) are used for a high level of allowable substitution between indicators of the same group. If the level of substitution is moderate, a balancing factor of 2 will suffice. A balancing factor of 3 reflects a situation of minimal substitution. The balancing factors were assumed to be crisp. Balancing factors are not well defined in current literature. However, analysis implies that as the balancing factor increases, the less influential the weights become. Therefore, the practical application of the balancing factor is not lost, since limiting the balancing factor to modest levels seems appropriate. For additional information on balancing factors, please refer to Bogardi (1992), Lee et al. $(1991,1992)$. 
To further illustrate this, consider factors that have the same units such as dollars. In that case, the model would choose between dollars or dollars indicating a high degree of exchangeability between the factors. This is similar to comparing 'apples to apples' and would be assigned a balancing factor of 1 . Contrast this to the units of the factors shown in Table 1. The units include dollars per hectare, tonnes of nitrogen per hectare, and millimeters of irrigation water. Since there is no common unit, there is a low degree of natural exchangeability between the factors, yet they must be combined. This is analogous to comparing 'apples to oranges' and is assigned a balancing factor of 3 . By extension it is obvious that the groups could fall somewhere between the previous two explanations and would be assigned a balancing factor of 2. This is analogous to comparing 'Red Delicious apples to Jonathan apples'. The utility of the balancing factor is to combine and compare dissimilar interest. It should be noted that the DM has the freedom to assign the balancing factor to a value that is appropriate without regard for the commonality of the unit. This is important if the DM will genuinely exchange, as in this example, tonnes of nitrogen per hectare with millimeters of irrigation water with dollars per hectare. The range of $1-3$ is a sufficient limit for balancing factors but can also be represented as fuzzy number (Jones and Jones, 1999).

The weights and balancing factors could be valued as fuzzy variables, ranks, or scaled ranks to provide a more realistic description of the contributing factors. A spreadsheet calculator was developed to perform the calculations. Example outputs are shown in Figs. 6-9.

\section{References}

Arizona Cooperative Extension, 1996. Arizona 1996 Cotton Field Budget Tables. Department of Agriculture and Resource Economics, The University of Arizona, Tucson, AZ.

Baker, D.N., Lambert, J.R., McKinion, J.M., 1983. GOSSYM: a simulator of cotton crop growth and yield. S.C. Agricultural Experiment Station Technical Bulletin 1089, 134.

Barnes, E.M., Baker, M.G., 1999. Multispectral data for soil mapping: possibilities and limitations. Presented at the 1999 ASAE Annual International Meeting (Paper No. 991138). ASAE, St. Joseph, MI.

Bardossy, A., Duckstein, L., 1992. Analysis of a karstic aquifer management problem using fuzzy composite programming. Water Resources Bulletin 28 (1), 63-73.

Bardossy, A., Bogardi, I., Duckstein, L., 1985. Composite programming as an extension of compromise programming. In: Serfini, P. (Ed.), Mathematics of Multiple Objective Optimization. Springer Verlag, Vienna, Austria, pp. 375-408.

Blackmer, T.M., Schepers, Varvel, G.E., Walter-Shea, E.A., 1996. Nitrogen deficiency detection using reflected shortwave radiation from irrigated corn canopies. Agronomy Journal 88 (1), 1-5.

Bogardi, I., 1992. Environmental risk analysis. In: Proceedings of the International Symposium on Water, Development and the Environment. Williams, J., Niemczynowicz, J. and Lindh, A. (Eds.). Lewis Publishing, Boca Raton, FL, pp. 147-175.

Clarke, T.R., 1997. An empirical approach for detecting crop water stress using multispectral airborne sensors. Horticultural Technology 7, 9-16.

DiFrancesco, Lazzerini, F. B., Maggiore, A., Marcelloni, F., DeRossi, D., 1998. Electronic nose based on linguistic fuzzy classification. EUFIT, 98, 7-10 September 1998, pp. 1211-1215. ELITE Foundation, Aachen, Germany.

Dong, W., Shah, H.C., 1987. Vertex method for computing functions of fuzzy variables. Fuzzy Sets and Systems 24, 65-78. 
Fritz, L.W., 1996. The era of commercial earth observation satellites. Photogram. Eng. Remote Sens 62, $39-45$.

Hagemeister, M.E., Jones, D.D., Woldt, W.E., 1996. Hazard ranking of landfill using fuzzy composite programming. Journal of Environmental Engineerin ASCE 122 (4), 248-258.

Heilman, P., Yakowitz, D.S., Lane, L.J., 1997. Targeting farms to improve water quality. Applied Mathematics and Computation 83, 173-194.

Jackson, R.D., 1984. Remote sensing of vegetation characteristics for farm management. SPIE 475, 8196.

Jones, D., Jones, C.L., 1999. Strategic decision processes in information technology using fuzzy composite programming. EUFIT, 99, 13-16 September 1999. ELITE Foundation, Aachen, Germany.

Lawrence, P.A., Stone, J.J., Heilman, P., Lane, L.J., 1997. Using measured data and expert opinion in a multiple objective decision support system for semiarid rangelands. Transactions of the ASAE 40 (6), 1589-1897.

Lee, Y.W., Bogardi, I., Stansbury, J., 1991. Fuzzy decision making in dredged-material analysis. Journal of Environmental Engineering ASCE ( 117), 614-630.

Lee, Y.W., Dahab, M.F., Bogardi, I., 1992. Nitrate risk management under uncertainty. Journal Water Resources Planning and Management ASCE 118 (2), 151-165.

Marani, A., Cardon, G.E., Phene, C.J., 1992. CALGOS, a version of GOSSYM adapted for irrigated cotton I. drip irrigation, soil water transport and root growth. In: 1992 Proceedings of the Beltwide Cotton Conferences, Herber, J.D. (Ed.). Nashville, Tennessee, 6-10 January 1992. National Cotton Council, Memphis, TN. pp. 1352-1357.

Mauney, J.R., Kimball, B.A., Pinter, P.J., LaMorte, R.L., Lewin, K.F., Nagy, J., Hendrey, G.R., 1994. Growth and yield of cotton in response to a free-air carbon dioxide enrichment (FACE) environment. Agricultural and Forest Meteorology 70, 46-67.

Moran, M.S., Inoue, Y., Barnes, E.M., 1997a. Opportunities and limitations for image-based remote sensing in precision crop management. Remote Sensing of Environment 61 (3), 319-346.

Moran, S.M., Clarke, T.R., Qi, J., Pinter, Jr., P.J., 1996. MADMAC: A test of multispectral airborne imagery as a farm management tool. In: Proceedings of the 26th Symposium on Remote Sens. Environ., 25-29 March 1996, Vancouver, BC. International Center for Remote Sensing of Environment, Baltimore, Maryland, USA. pp. 612-617.

Moran, S.M., Clarke, T.R., Qi, J., Barnes, E.M., Pinter, P.J., 1997b. Practical techniques for conversion of airborne imagery to reflectances. In: Proceedings of the 16th Biennial Workshop on Videography and Color Photography in Resource Assessment. Everitt, J.H. (Ed.). Published by the American Society for Photogrammetry and Remote Sensing, 5410 Grosvenor Lane, Bethesda, MD 20814, pp. 82-95.

Moulin, S., Dondeau, A., Delecolle, R., 1998. Combining agricultural crop models and satellite observations from field to regional scales. International Journal of Remote Sensing 19 (6), 1021-1036.

Pinter Jr., P.J., 1993. Solar angle independence in the relationship between absorbed PAR and remotely sensed data for alfalfa. Remote Sensing of Environment 46 (1), 19-25.

Pinter Jr., P.J., Kimball, B.A., Mauney, J.R., Hendrey, G.R., Lewin, K.F., Nagy, J., 1994. Effects of freeair carbon dioxide enrichment on PAR absorption and conversion efficiency by cotton. Agricultural and Forest Meteorology 70, 209-230.

Robert, P.C., Rust, R.H., Larson, W.E., 1995. Preface. In: Proceedings of Site-Specific Management for Agricultural Systems, Minneapolis, Minnesota, 27-30 March, Robert, P.C., Rust, R.H. and Larson, W.E. (Eds.). American Society of Agronomy, Madison, WI, pp. xiii-xiv.

Ross, T.J., 1995. Fuzzy Logic with Engineering Applications. McGraw-Hill, Inc., New York.

Usery, L.E., Pocknee, S., Boydell, B., 1995. Precision farming data management using geographic information systems. Photogrammetric Engineering and Remote Sensing 61 (11), 1383-1391.

Wei, M., Weber, F., 1995. Decision making for waste management. Chemical Engineering Communications 134, 133-145.

Woldt, W.E., Bogardi, I., 1992. Ground water monitoring network design using multi criteria decision making and geostatistics. Water Resources Bulletin 28 (1), 45-61.

Yakowitz, D.S., Hipel, K.W., 1997. Multiple objective decision making for "lokahi" (balance) in environmental management. Applied Mathematics and Computation 83, 97-115. 
Yakowitz, D.S., Lane, L.J., Szidarovszky, F., 1993. Multi-attribute decision making: dominance with respect to an importance order of the attributes. Applied Mathematics and Computation 54 (2\&3), 167-187.

Zadeh, L., 1965. Fuzzy sets. Information and Control 8 (3), 338-353.

Zeleny, M., 1973. Compromise programming. In: Multiple Criteria Decision Making. Cochran, J.L. and Zeleny, M. (Eds.), University of South Carolina Press, Columbia, SC, USA. pp. 263-301. 